\title{
Rural Residence and Diagnostic Delay for Amyotrophic Lateral Sclerosis in Saskatchewan
}

\author{
Melissa Diane Armstrong, Gregory Hansen, Kerri Lynn Schellenberg
}

\begin{abstract}
Background: Diagnostic delay in amyotrophic lateral sclerosis (ALS) is common. In a recent Canadian study evaluating provincial differences in care, Saskatchewan had the longest delay at 27 months. Since Saskatchewan has a large rural population, this study sought to determine whether geographically determined access to a neurologist at tertiary centers could be contributing to this lengthy delay. Methods: A retrospective chart review of 171 patients seen in the ALS clinic in Saskatoon, Saskatchewan was performed. Urban or rural location, distance from nearest tertiary center, and clinically relevant data were collected. Results: There was no difference between urban and rural populations for delay in symptom onset to diagnosis. For rural patients, linear regression modeling did not uncover a significant relationship between distance from tertiary center and time to diagnosis. Additionally, there were no differences between urban and rural dwellers either for referral or utilization of feeding tube, noninvasive ventilation, riluzole, or communication devices. Contrary to the previous data showing a 27-month diagnostic delay in Saskatchewan, our study which included a larger provincial population found the mean diagnostic delay was 16.6 months. Conclusions: This study did not uncover differences in diagnostic delay or ALS care between urban and rural dwellers. Further study is required to determine reproducibility of results.
\end{abstract}

RÉSUMÉ : Délais de diagnostic de la sclérose latérale amyotrophique lorsqu'on réside en Saskatchewan en milieu rural. Contexte : Les délais de diagnostic pour la sclérose latérale amyotrophique (SLA) sont fréquents. Dans une récente étude canadienne visant à évaluer les différences provinciales en matière de soins, la Saskatchewan est apparue comme la province où de tels délais (27 mois) étaient les plus longs. Étant donné que cette province possède une importante population rurale, la présente étude a cherché à déterminer si l'accès à des neurologues dans des centres de santé tertiaires en fonction de critères géographiques contribuait à ces longs délais. Méthodes : Nous avons ainsi effectué une analyse rétrospective des dossiers de 171 patients vus à Saskatoon dans une clinique de la SLA. Nous avons aussi collecté des données pertinentes sur le plan clinique ainsi que des données visant à déterminer l'emplacement des patients (milieu urbain ou rural) ainsi que la distance les séparant du centre de santé tertiaire le plus proche. Résultats : En matière de délais entre les premiers symptômes de SLA et un diagnostic, aucune différence n'a été observée entre les patients vivant en ville et ceux vivant en campagne. Pour ces derniers, une modélisation de la régression linéaire n'a pas permis de découvrir une association significative entre la distance les séparant d'un centre de santé tertiaire et le moment où un diagnostic a été posé. Plus encore, aucune différence n'a été notée entre les patients des villes et des campagnes pour ce qui est de l'aiguillage vers un spécialiste, de l'utilisation d'une sonde d'alimentation ou du recours à la ventilation non invasive, au riluzole ou à des appareils de communication. Contrairement aux données précédentes révélant un délai de 27 mois avant d'obtenir en Saskatchewan un diagnostic, notre étude, qui comprenait un échantillon plus vaste, a conclu que les délais moyens avant de poser un diagnostic étaient de 16,6 mois. Conclusions : Cette étude n'a pas mis en relief des différences entre patients des villes et de la campagne en ce qui regarde les délais de diagnostic de la SLA et les soins prodigués aux patients. Il n'empêche que des études plus approfondies demeurent nécessaires afin de déterminer la reproductibilité de ces résultats.

Keywords: ALS, Diagnostic delay, Rural

doi:10.1017/cjn.2020.38

Can J Neurol Sci. 2020; 47: 538-542

\section{INTRODUCTION}

Amyotrophic lateral sclerosis (ALS) is a devastating neurologic disease characterized by progressive loss of limb, respiratory, and bulbar function. The life expectancy from disease onset is approximately $2-5$ years. Although there is no cure, an early diagnosis can reduce patient and family anxiety, limit the number of unnecessary diagnostic tests, and maximize the management strategies that exist. ${ }^{1}$

Unfortunately, patients with ALS routinely experience a lag between symptom onset and diagnosis. ${ }^{2}$ The established risk factors for these diagnostic delays include age greater than 60 years, sporadic illness (as opposed to familial ALS), limb onset,

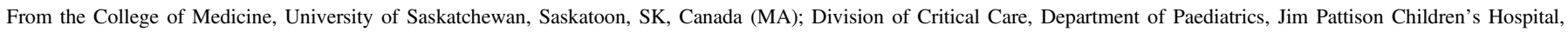
Saskatoon, SK, Canada (GH); Division of Neurology, Department of Medicine, University of Saskatchewan, Saskatoon, SK, Canada (KS)

Received September 27, 2019. Final Revisions Submitted February 12, 2020. Date of Acceptance February 13, 2020.

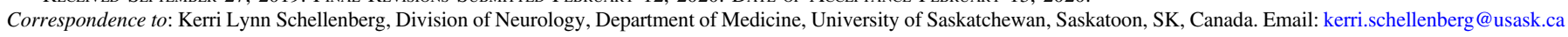


slowly progressive disease, ${ }^{1,2}$ delay from primary to secondary services, and in some cases, male gender. ${ }^{3}$ Another potential contributor to delay is that ALS is a diagnosis of exclusion, made when other potential mimickers have been ruled out. ${ }^{4}$

Nonclinical risk factors, such as urban versus rural living, have previously been queried as potential sources of diagnostic delay. ${ }^{1,5}$ In a recently published Canadian study, mean time of diagnostic delay was significantly different between provinces. ${ }^{6}$ Saskatchewan was found to have the longest delay at 27 months, almost double that of some other provinces, but the reasons for this delay were not elucidated. As Saskatchewan has a very large rural and remote population, we sought to explore the possibility of a link between diagnostic delay and distance from tertiary health centers. To our knowledge, this is the first study evaluating the relationship between diagnostic delay in ALS and urban versus rural dwelling.

\section{Patients/Methods}

\section{Subjects}

This retrospective chart review included all 182 patients with ALS referred to a tertiary ALS clinic in Saskatoon between 2000 and 2016. Eleven charts had incomplete data and were excluded, leaving 171 complete charts for analysis. Patients with other motor neuron disease, such as progressive muscular atrophy and primary lateral sclerosis, were excluded. The patient's age, sex, place of residence, location from which the referral was made, site of symptom onset, date of symptom onset, date of diagnosis, first appointment in clinic, number of clinic visits, and date of death were recorded. ALS management including utilization of riluzole and communication devices and referral for feeding tube and noninvasive ventilation (NIV) were also charted. Ethics approval was granted by the University of Saskatchewan.

\section{Local Context}

The 2016 census indicated that there are just over 1.1 million Saskatchewan residents, in a province approximately $651,000 \mathrm{~km}^{2}$. $^{7}$ Over 245,000 resided in Saskatoon; 235,000 in Regina, and all other urban centers had populations less than $36,000{ }^{8}$ For purposes of this study, urban residence was defined as residing within $20 \mathrm{~km}$ from Saskatoon or Regina. Only Saskatoon and Regina have neurologists in practice, therefore all patients must be referred to these centers for assessment and diagnosis of ALS. During the time period of this study, the diagnosis of ALS was made by a neurologist in Saskatoon or Regina, after which point the patient was referred to a physiatrist at the ALS clinic in Saskatoon for ongoing care. The ALS clinic was not multidisciplinary, but serviced by single physicians who would refer to other specialists and health practitioners according to the patients' needs.

\section{Statistics}

The primary variable was time from symptom onset to ALS diagnosis. The secondary variables included urban and rural differences between ALS clinic access and management. For univariate data presented as proportions, Chi-square statistics were utilized. Kruskal-Wallis ANOVAs were used to compare clinical time metrics. Kaplan-Meier survival curves and log-rank tests were used to assess time of symptom onset and first ALS

\section{Table 1: Patient demographics}

\begin{tabular}{|c|c|}
\hline \multicolumn{2}{|l|}{ Characteristics } \\
\hline Total number of patients, $n$ & 171 \\
\hline Male sex, $n(\%)$ & $104(60.8)$ \\
\hline Mean (standard deviation) age of ALS symptom onset, years & $64.3(10.9)$ \\
\hline $\begin{array}{l}\text { Mean (standard deviation) survival duration from symptom } \\
\text { onset, months }\end{array}$ & $39.1(17.2)$ \\
\hline Number urban patients, $n(\%)$ & $78(45.6)$ \\
\hline Saskatoon dwellers, $n(\%)$ & $62(36.2)$ \\
\hline Number of rural patients, $n(\%)$ & $93(54.4)$ \\
\hline$<100 \mathrm{~km}$ from closest urban center, $n(\%)$ & $26(15.2)$ \\
\hline $100-199 \mathrm{~km}$ from closest urban center, $n(\%)$ & $42(24.6)$ \\
\hline $200-299 \mathrm{~km}$ from closest urban center, $n(\%)$ & $19(11.1)$ \\
\hline $300-399 \mathrm{~km}$ from closest urban center, $n(\%)$ & $2(1.2)$ \\
\hline $400+\mathrm{km}$ from closest urban center, $n(\%)$ & $4(2.3)$ \\
\hline \multicolumn{2}{|l|}{ Site of onset: } \\
\hline Limb, $n(\%)$ & $98(57.3)$ \\
\hline Bulbar, $n(\%)$ & $56(32.7)$ \\
\hline Neck drop, $n(\%)$ & $5(2.9)$ \\
\hline Respiratory, $n(\%)$ & $3(1.8)$ \\
\hline Weight loss, $n(\%)$ & $2(1.23)$ \\
\hline Combination of symptoms, $n(\%)$ & $7(4.1)$ \\
\hline
\end{tabular}

clinic visit to death. Post hoc analysis of rural patients included simple linear regression modeling for time of symptom onset to diagnosis and distance to the nearest tertiary referral center. $p$ Values less than 0.05 were considered significant.

\section{Results}

Patient characteristics are summarized in Table 1. A total of 78 (45.6\%) urban and $93(54.5 \%)$ rural patients were evaluated, 104 $(60.8 \%)$ male and $67(39.2 \%)$ female. Rural dwellings ranged between 21 and $1118 \mathrm{~km}$ from the closest urban center with the majority of rural patients living between 100 and $300 \mathrm{~km}$ from the closest urban center. There were 0 patients between 1 and $20 \mathrm{~km}, 8$ patients were within $21-50 \mathrm{~km}$, and 18 patients within $51-100 \mathrm{~km}$ from Saskatoon or Regina. Mean age at symptom onset was 64.3 years. Limb onset was the most common presentation $(57.3 \%)$, followed by bulbar onset $(32.7 \%)$ with other presentations occurring less commonly. The mean diagnostic delay was 16.6 months.

There were no differences between urban and rural patients with time from symptom onset to diagnosis, symptom onset to first clinic visit, and time from diagnosis to clinic visit (Table 2). The were also no survival differences (Figures 1 and 2) from median time of syptom onset [27.0 (95\% CI 23.8-30.2) versus 34.0 (95\% CI 28.4-39.6) months; log-rank significance 0.44$]$ or first ALS clinic visit to death [14.0 (95\% CI 9.9-18.1) versus 18 (95\% CI 13.3-22.8) months; log-rank significance 0.39]. For rural patients, linear regression modeling did not find a significant relationship between distance to referral tertiary center and time of ALS diagnosis $[F(1,95)=1.47 ; p=0.23 ; R 2=0.015]$. 
Table 2: Clinical differences between rural and urban patients with ALS

\begin{tabular}{l|c|c|c}
\hline Clinical time metric & Urban $^{\mathbf{a}}$ & Rural $^{\mathbf{a}}$ & $\boldsymbol{p}$-Value \\
\hline $\begin{array}{l}\text { Time from symptom onset } \\
\text { to diagnosis (months) }\end{array}$ & $10(6-17)$ & $12(8-19)$ & 0.08 \\
\hline $\begin{array}{l}\text { Time from symptom onset } \\
\text { to first clinic visit (months) }\end{array}$ & $13(7-20)$ & $14(9.5-20.5)$ & 0.13 \\
\hline $\begin{array}{l}\text { Time from diagnosis to } \\
\text { clinic visit (months) }\end{array}$ & $1(0.5-2)$ & $1(0.5-2)$ & 0.76 \\
\hline
\end{tabular}

ALS = amyotrophic lateral sclerosis.

${ }^{\mathrm{a}}$ Median (interquartile range).

${ }^{\mathrm{b}}$ Kruskal-Wallis ANOVA.

Table 3: ALS management of rural and urban patients

\begin{tabular}{|c|c|c|c|}
\hline Management metric & Urban & Rural & $p$-Value \\
\hline Referral for feeding tube & $54 \%$ & $53 \%$ & 0.81 \\
\hline $\begin{array}{l}\text { Utilization of feeding tube if } \\
\text { referred }\end{array}$ & $62 \%$ & $47 \%$ & 0.16 \\
\hline Referral for NIV & $63 \%$ & $60 \%$ & 0.59 \\
\hline Utilization of NIV if referred & $27 \%$ & $26 \%$ & 0.89 \\
\hline Riluzole offered & $76 \%$ & $83 \%$ & 0.25 \\
\hline Utilization of riluzole if offered & $76 \%$ & $85 \%$ & 0.19 \\
\hline Communication device offered & $34 \%$ & $24 \%$ & 0.15 \\
\hline $\begin{array}{l}\text { Utilization of communication } \\
\text { device if offered }\end{array}$ & $68 \%$ & $74 \%$ & 0.65 \\
\hline Number of total clinic visits ${ }^{\mathrm{a}}$ & $2(1-5)$ & $2(1-4)$ & $0.26^{\mathrm{b}}$ \\
\hline
\end{tabular}

$\mathrm{ALS}=$ amyotrophic lateral sclerosis; NIV $=$ noninvasive ventilation.

${ }^{\mathrm{a}}$ Median (interquartile).

${ }^{\mathrm{b}}$ Kruskal-Wallis ANOVA.

There were no differences between urban and rural dwellers for referral for interventions, including feeding tube, noninvasive ventilation, riluzole usage, and communication devices. Utilization rates for the above interventions also did not differ between the two groups. Both urban and rural patients attended the clinic with equivalent frequency (Table 3). King's scoring for ALS staging was available for 165 patients ( 90 rural, 75 urban). Rural patients presented for first clinic visit in the following King's score categories: $2 \mathrm{a}=15(17 \%), 2 \mathrm{~b}=45(50 \%)$, and $3=30(33 \%)$. A similar pattern was seen for urban patients: $2 \mathrm{a}=13(17 \%), 2 \mathrm{~b}=28$ $(37 \%)$, and $3=29(39 \%)$, with a few patients presenting in latter stages of disease: $4 \mathrm{a}=3(4 \%)$ and $4 \mathrm{~b}=2(3 \%)$.

\section{Discussion}

For our purposes, we have considered patients outside of Regina or Saskatoon to be "rural". We feel this is justified given the fact that these smaller centers in Saskatchewan would be effectively considered remote with respect to access to neurology, since there are neurologists only in Regina and Saskatoon. In our study, there was no difference in diagnostic delay for rural patients, and despite the large remote population in Saskatchewan, linear regression modeling did not uncover a relationship between the distance from an urban center and diagnostic delay.

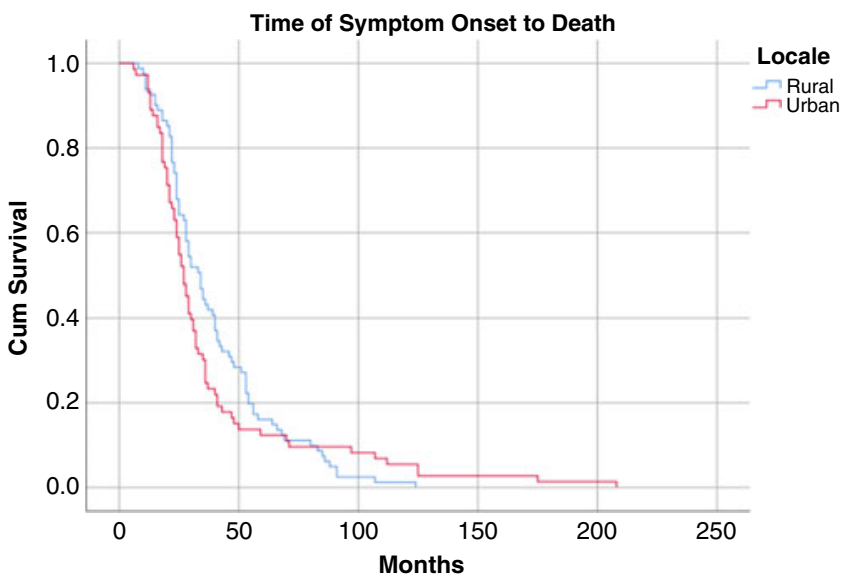

Figure 1: Kaplan-Meier survival curve from syptom onset.

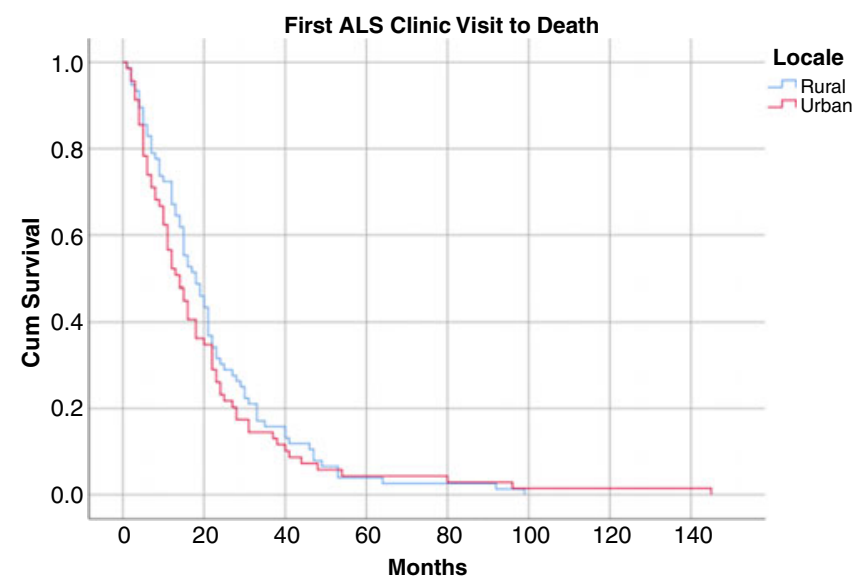

Figure 2: Kaplan-Meier survival curve from first ALS clinic visit.

While some attention has been paid to the relationship between geospatial factors and incidence, prevalence, and survival in $\mathrm{ALS},{ }^{9-16}$ to our knowledge, the relationship between diagnostic delay in ALS and urban versus rural dwelling is largely unstudied, aside from one paper origininating from the Cantabria region of Northern Spain. ${ }^{13}$ While not the focus of this study, the median time to diagnosis did differ between groups (4.8 months for urban vs 9.1 months for rural dwellers); however, there are some limitations with interpreting the significance of this finding; while the total number of patients was 53, there is no documentation of the actual number of rural patients included in the study nor is there any information regarding their distance from the tertiary center. Our study, while still small, presents more than three times the number of patients included in the Spanish study. Saskatchewan's geography and demographics also differs significantly from the region described in this article. Cantabria's area is $5289 \mathrm{~km}^{2}$ with a reported catchment population of $300,000,{ }^{13,14}$ and Saskatchewan's area is $651,036 \mathrm{~km}^{2}$ with a population of 1.1 million. ${ }^{7}$ It is difficult to compare such a small and comparatively densely populated region with Saskatchewan's large territory and sparse population.

Internationally, rural dwelling has been cited as a cause for diagnostic delay in diseases, such as tuberculosis, cancers, congenital hearing loss, and dementia. ${ }^{17-20}$ Explanations have 
included travel distance, a higher likelihood that patients would seek alternative/traditional medical care first, ${ }^{19}$ and lack of education. ${ }^{18}$ In Saskatchewan, rural patients with dementia experienced diagnostic delay because caregivers had a lack of confidence in their local healthcare center and felt that their privacy may not be maintained. ${ }^{18}$ Consequently, formal support services were utilized only after the patient could not be cared for adequately at home. ${ }^{18}$ This is congruent with a Canadian systematic review that reported many rural dwellers with chronic disease in Canada are more hesitant to seek healthcare services until their disease is prohibitive to their ability to work. ${ }^{13}$ The lack of difference in diagnostic delay for our rural cohort might be explained by the rapid neurologic decline of ALS resulting in significant disability, and the loss of physical independence prompting medical attention.

An additional barrier to receiving adequate specialist care is the distance needed to travel. A study evaluating the usefulness of telehealth for dementia care in Saskatchewan showed that such a system would save patients an average of $426 \mathrm{~km}$ per round trip - a distance that may be prohibitive to some patients from attending follow-up care or utilizing a multidisciplinary clinic. ${ }^{21}$ Compounding this issue, travel in the winter in Canada can be particularly challenging and has been cited as a factor preventing rural dwellers from accessing healthcare. ${ }^{22}$ A study of patients and caregivers who attended the recently developed multidisciplinary ALS clinic in Saskatchewan cited travel (including inclement weather) as the only barrier to clinic attendance. ${ }^{23}$ These barriers considered it is somewhat surprising that even the most remote dwellers did not incur a difference in diagnostic delay.

The system of healthcare delivery may be a factor mitigating the rural versus urban discrepancy in diagnostic delay. In 2014, a Spanish study found that the greatest delay occurred between the first consultation with a non-neurologist and the assessment by a neurologist (with referral delay influenced by the patient's symptoms and age). Patients assessed by a neurologist at the first or second consultation had a significantly shorter diagnostic delay. ${ }^{3}$ Furthermore, it has been shown that a shortage of neurologists in rural areas can create diagnostic delay. ${ }^{24}$ However, the lack of discrepancy between urban and rural residents in Saskatchewan may be partly due to the existing healthcare system. Primary care physicians are the gatekeepers to secondary and tertiary care available in urban centers; this is consistent for both rural and urban dwellers. Furthermore, both rural and urban patients are placed on waitlists for the same specialists in urban centers; therefore, there is little discrepancy between the waitlist times of urban and rural patients.

Another important consideration is differences in attitude toward formal medical treatment and management. Studies of diagnostic delay in Kenya, Ethiopia, and Morocco show that some rural patients sought alternative, traditional treatments that were better understood by the community. ${ }^{18,19,25}$ Although recognizing that the urban/rural discrepancies in these countries may not be applicable to a Saskatchewan population, it might be assumed that rural patients find interventions, such as the insertion of feeding tubes, NIV, riluzole, or use of communication devices less palatable than their urban counterparts. However, our study found that these medical interventions were utilized equally in both rural and urban populations. Of note, both rural and urban patients attended an equal number of clinic visits, which may speak to the engagement of rural patients in the clinic processes.
This may also partly explain why geospatial factors in Saskatchewan were inconsequential to patient life span after first symptom onset - a finding consistent with the 2016 study in Ireland that found that distance from dwelling to the ALS multidisciplinary clinic had no bearing on survival. ${ }^{9}$

Lastly, while a recent study on provincial differences in ALS care in Canada found Saskatchewan to have the longest diagnostic delay at 27 months, ${ }^{6}$ our study shows Saskatchewan's diagnostic delay to be an average of 16.5 months - a timeline more consistent with the previously reported provincial averages (mean time to diagnosis 21 months; range 15.1-27.0 months). It has been previously noted that slower progressors may be more likely to be referred to multidisciplinary clinics, ${ }^{26,27}$ and slower progression is also associated with diagnostic delay. ${ }^{1,2}$ Since the previous Canadian study enrolled a small number from Saskatchewan $(n=22)$, a recruitment bias is possible whereby the patients attending the clinic were slower progressors thus spending more time in clinic and therefore more likely to be enrolled.

\section{LIMITATIONS}

Only patients seen at the ALS clinic located in Saskatoon were included in the study; therefore, it is likely that we did not capture all ALS patients in the province and may have missed a discrepancy if one exists. It is known that some patients with ALS were referred to multidisciplinary ALS clinics situated out of province during the era in which these data were collected. Also, it is possible that patients diagnosed at advanced stages of the disease might not wish to travel to a clinic which could be distant from their place of residence. As such, a selection bias exists whereby patients who were unable to tolerate travel would not have attended, and some patients who preferred to travel out of province for multidisciplinary care would not have been included. However, our sample of patients did attend included both urban and rural patients and well represents each demographic.

Due to the long diagnostic delay, it is possible that as the disease limited independent function, some of the patients moved to Saskatoon or Regina in order to receive more intensive care afforded by an urban center prior to their official diagnosis. These patients' newly acquired urban address would artificially inflate the number of urban dwellers. However, it is unlikely that this would have been a phenomenon widespread enough to affect the results of this study.

A significant limitation is that this is a single-center retrospective study, and further studies would be useful to demonstrate generalizability; further review with a national registry would be valuable. Saskatchewan is a province with a low population, and consequently our sample size is relatively small. However, with its large rural population subject to the same health access as urban dwellers, Saskatchewan offers an ideal population to study the impact of geography on diagnostic delay.

\section{Conclusions}

To our knowledge, this is the first study to assess the relationship between diagnostic delay and rural/urban dwelling among ALS patients. While rural residence has been shown to increase diagnostic delay in the case of other diseases, our study found no association between rural location and delay. This finding held for rural patients living in rural settings situated relatively close to urban centers $(<100 \mathrm{~km})$ as well as rural 
dwellers living very remotely from urban centers $(>400 \mathrm{~km})$. Furthermore, rural Saskatchewan residents were as equally likely to receive medical intervention as their urban counterparts.

Additional studies of this relationship between rural/urban dwelling and diagnostic delay in ALS are needed in order to demonstrate whether this finding is reproducible.

\section{ACKNOWLEDgMenTs}

This project was supported by a Dean's Project Award funded by the College of Medicine at the University of Saskatchewan in Saskatoon, Canada.

\section{DisClosures}

The authors do not have any relevant disclosures.

\section{Statement of Authorship}

KS: Conception of research idea and study design, supervision of literature review, and manuscript writing and editing. $\mathrm{GH}$ : Contribution to study design, statistical analysis, and manuscript writing and editing. MA: Data collection, literature review, and manuscript writing.

\section{REFERENCES}

1. Paganoni S, Macklin EA, Lee A, et al. Diagnostic timelines and delays in diagnosing amyotrophic lateral sclerosis (ALS). Amyotroph Lat Scl Fr. 2014 Sep 1;15(5-6):453-6.

2. Hardiman O, Van Den Berg LH, Kiernan MC. Clinical diagnosis and management of amyotrophic lateral sclerosis. Nat Rev Neurol. 2011 Nov;7(11):639.

3. Nzwalo H, de Abreu D, Swash M, Pinto S, de Carvalho M. Delayed diagnosis in ALS: the problem continues. J Neurol Sci. 2014 Aug 15;343(1-2):173-5.

4. Cellura E, Spataro R, Taiello AC, La Bella V. Factors affecting the diagnostic delay in amyotrophic lateral sclerosis. Clin Neurol Neurosurg. 2012 Jul 1;114(6):550-4.

5. Aoun SM, Breen LJ, Edis R, et al. Breaking the news of a diagnosis of motor neurone disease: a national survey of neurologists' perspectives. J Neurol Sci. 2016 Aug 15;367:368-74.

6. Hodgkinson VL, Lounsberry J, Mirian A, et al. Provincial differences in the diagnosis and care of amyotrophic lateral sclerosis. Can J Neurol Sci. 2018 Nov;45(6):652-9.

7. Statistics Canada. [Internet] Census Profile, 2016 Census - Saskatchewan [Province] and Canada [Country]. Available from: https:// www12.statcan.gc.ca/census-recensement/2016/dp-pd/prof/details/ Page.cfm?Lang $=$ E $\&$ Geo $1=$ PR $\&$ Code $1=47 \&$ Geo $2=\&$ Code $2=$ $\&$ SearchText $=$ Saskatchewan $\&$ SearchType $=$ Begins $\&$ SearchPR $=$ $01 \& \mathrm{~B} 1=\mathrm{All} \&$ GeoLevel $=$ PR $\&$ GeoCode $=47 \&$ type $=0$; accessed September 15, 2019.

8. Statistics Canada. [Internet] Census Profile, 2016 Census - Select from a list - Saskatchewan. Available from: https://www12.statcan.gc.ca/ census-recensement/2016/dp-pd/prof/search-recherche/lst/resultsresultats.cfm?Lang $=\mathrm{E} \& \mathrm{GeoCode}=47 \& \mathrm{TABID}=1 \& \mathrm{G}=1 \& \mathrm{Geo} 1=$ $\&$ Code $1=\&$ Geo $2=\&$ Code $2=\&$ type $=0 ;$ accessed September 15 , 2019.
9. Rooney J, Heverin M, Vajda A, et al. Survival analysis of geospatial factors in the Irish ALS cohort. Amyotroph Lat Scl Fr. 2016 Nov 16;17(7-8):555-60.

10. Aksoy D, Cevik B, Solmaz V, Kurt SG. Clinical, Demographic and prognostic features of sporadic amyotrophic lateral sclerosis in Northern Turkey. Int J Neurosci. 2014 Jan 1;124(1):68-73.

11. Mandrioli J, Biguzzi S, Guidi C, et al. Epidemiology of amyotrophic lateral sclerosis in Emilia Romagna Region (Italy): a population based study. Amyotroph Lat Scl Fr. 2014 Jun 1;15(3-4):262-8.

12. Mandrioli J, Faglioni P, Merelli E, Sola P. The epidemiology of ALS in Modena, Italy. Neurology. 2003 Feb 25;60(4):683-9.

13. Riancho J, Lozano-Cuesta P, Santurtun A, et al. Amytrophic Lateral Sclerosis in Northern Spain 40 years later: What has changed? Neurodegener Dis. 2016 May 19;16:337-41.

14. Lopez-Vega J, Calleja O, Combarros J, et al. Motor Neuron Disease in Cantabria. Acta Neurol Scand. 1988; 77:1-5.

15. Murphy M, Quinn S, Young J et al. Increasing incidence of ALS in Canterbury, New Zealand. Neurology. 2008 71;1889-95.

16. Traynor B, Codd M, Corr B, et al. Incidence and prevalence of ALS in Ireland, 1995-1997: a population-based study. Neurology. 1999 Feb; 52(3):504-9.

17. Ngwira LG, Dowdy DW, Khundi M, et al. Delay in seeking care for tuberculosis symptoms among adults newly diagnosed with HIV in rural Malawi. Int J Tuberc Lung Dis. 2018 Mar 1; 22(3):280-6.

18. Kisiangani J, Baliddawa J, Marinda P, et al. Determinants of breast cancer early detection for cues to expanded control and care: the lived experiences among women from Western Kenya. BMC Women's Health. 2018 Dec;18(1):81.

19. Yimer SA, Bjune GA, Holm-Hansen C. Time to first consultation, diagnosis and treatment of TB among patients attending a referral hospital in Northwest, Ethiopia. BMC Infect Dis. 2014 Dec;14(1):19.

20. Williams F, Thompson E. Disparity in breast cancer late stage at diagnosis in missouri: does rural versus urban residence matter? J Racial Ethn Health Disparities. 2016 Jun 1;3(2):233-9.

21. Dal Bello-Haas V, Cammer A, Morgan D, Stewart N, Kosteniuk J. Rural and remote dementia care challenges and needs: perspectives of formal and informal care providers residing in Saskatchewan, Canada. Rura Remote Health. 2014 Aug $1 ; 14(3): 2747$.

22. Brundisini F, Giacomini M, DeJean D, Vanstone M, Winsor S, Smith A. Chronic disease patients' experiences with accessing health care in rural and remote areas: a systematic review and qualitative meta-synthesis. Ont Health Technol Assess Ser. 2013;13(15):1.

23. Schellenberg KL, Hansen G. Patient perspectives on transitioning to amyotrophic lateral sclerosis multidisciplinary clinics. J Multidiscip Healthc. 2018;11:519.

24. Sato K, Morimoto N, Deguchi K, Ikeda Y, Matsuura T, Abe K. Seven amyotrophic lateral sclerosis patients diagnosed only after development of respiratory failure. J Clin Neurosci. 2014 Aug $1 ; 21(8): 1341-3$.

25. Maghous A, Rais F, Ahid S, et al. Factors influencing diagnosis delay of advanced breast cancer in Moroccan women. BMC Cancer. 2016 Dec;16(1):356.

26. Hutchinson M, Galvin R, Sweeney B, Lynch T, Murphy R, Redmond J. Effect of a multidisciplinary clinic on survival in amyotrophic lateral sclerosis. J Neurol Neurosurg Psychiatry. 2004 Aug 1;75(8):1208-9.

27. Lee JR, Annegers JF, Appel SH. Prognosis of amyotrophic lateral sclerosis and the effect of referral selection. J Neurol Sci. 1995 Oct 1;132(2):207-15. 